\title{
The demand incidence of cataract in Asian immigrants to Britain and their descendants
}

\author{
JOHN R THOMPSON \\ From the Department of Ophthalmology, University of Leicester School of Medicine, Leicester Royal \\ Infirmary, PO Box 65, Leicester LE2 7LX
}

SUMmARY Cataract is known to be more common in India than it is in the industrialised world, but there is little evidence to show whether people emigrating from India will continue to have a high incidence of the disease. Data have been collected from the outpatient clinics of a hospital in Leicester, England, that suggest that for people aged over 45 the demand incidence of cataract is more than five times higher in people of Indian descent than it is in the indigenous population. As well as measuring the demand incidence of cataract in Leicester's two main racial groups the data are used to investigate other risk factors. For both communities the demand incidence of cataract is significantly higher in women than in men, and it is significantly higher in people of Indian descent who emigrated directly from India than in those who emigrated from East Africa. Religious subgroups within the immigrant community also show small differences in their demand incidence. The possibility that these differences are linked to diet is considered.

It has frequently been observed that senile cataract is more common in developing countries than it is in industrialised countries. The Indian subcontinent has been reported as having an especially high prevalence of cataract, ${ }^{1-4}$ with one study in the Punjab ${ }^{3}$ finding a prevalence that varied with age between three and six times that found in the Framingham Eye Study. ${ }^{\text {s6 }}$

It is not at all clear why senile cataract should be more common in India than it is in industrialised countries. However, large epidemiological studies of eye disease and reviews of the risk factors for cataract do give us some clues. ${ }^{5-9}$ Among the risk factors that have been investigated are sex, ${ }^{10}$ a family history of the disease,, 1 diet, ${ }^{312}$ environmental factors, particularly sunlight, ${ }^{1,-15}$ socioeconomic factors such as poor education, ${ }^{7}$ and medical conditions including diabetes, ${ }^{9}$ and previous severe diarrhoea. ${ }^{17}$ It has also been suggested that some of the observed differences between populations may be due to differences in study methodology and definitions. ${ }^{8}$

A high rate of cataract among people of Indian descent is of particular interest in Britain because in the $1950 \mathrm{~s}, 1960 \mathrm{~s}$, and 1970s large numbers of indians

Correspondence to Mr J R Thompson. came to live in this country. At first they came mainly from the Indian subcontinent itself, but later many descendants of Indian families came to Britain after being expelled from their adopted countries in East Africa. Leicester is one of the cities where the immigrants chose to settle, and they now constitute about a quarter of the city's population.

\section{Material and methods}

The Leicester Royal Infirmary is the centre for eye care for the whole county of Leicestershire, and the ophthalmology department has recently been engaged in a major workload survey of its outpatient clinics. ${ }^{18}$ The survey started on 1 September 1981 , and results from the first two and a half years of data collection have been used as the basis for measurements of the demand incidence of cataract, that is, the number of new cases of cataract presenting at the hospital per 100000 population per year. The survey included everyone seen at the outpatient clinics during the time of the study. The data collected on each patient included their age, sex, the postcode of their address, their ethnic origin, country of birth, religion, and whether or not this was their first outpatient eye appointment. The survey also took 
the ophthalmologist's diagnoses and coded them according to the 9th revision of the International Classification of Diseases. ${ }^{19}$

To calculate demand incidence rates information is needed on the population structure of the catchment area of the hospital. As the Royal Infirmary is the centre for ophthalmology in Leicestershire, all cases of cataract among people resident in the county should in theory be seen there. However, there will be some loss of cases round the edge of the region when people choose to travel to other centres such as Derby, Nottingham, or Coventry. The Indian community of Leicestershire is largely confined to the City of Leicester, and very few people from any ethnic group who live in the city are likely to travel out of the region for eye care.

The structure of the population of the City of Leicester was studied in detail in a $16 \%$ household survey carried out in the spring of 1983 at the request of the City and County Councils. ${ }^{20}$ To make use of the detailed information available on the city's population and to avoid problems of loss of cases across the boundaries of the county the analysis presented below has been restricted to persons living within the city. Everyone who visited the outpatient clinic was classified on the basis of their postcode to decide whether or not they should be included in the analysis.

The outpatient clinic studied in the workload survey is intended for the treatment of adults, though children aged under 16 are occasionally seen. To avoid problems associated with partial coverage and because juvenile cataract probably has a different aetiology from age related cataract, persons under the age of 16 were excluded.

The demand incidence rates were calculated by dividing the number of new cases of cataract, obtained from the hospital survey, by the appropriate population estimates as obtained from the household survey. The rates have been analysed and adjusted for age by means of a method of indirect standardisation, ${ }^{21}{ }^{22}$ with the calculations performed with GLIM. ${ }^{23}$

\section{Results}

Table 1 shows the average demand incidence rates obtained in the study. Without any adjustments for age the rates are seen to be generally higher in women than men and in people of Indian rather than Caucasian descent. Age specific rates are given in Table 2 and the variation with age is illustrated by Fig. 1. This plot shows that the average demand incidence of cataract increases steadily with age in all groups, and confirms that the rates are consistently higher in women and in Indians. When indirect standardisation is used to smooth these data, Fig. 2 is
Table 1 The number of cases and demand incidence for Leicester residents by race and sex. Numbers relate to the period September 1981 to March 1984

\begin{tabular}{llcl}
\hline & & Number & $\begin{array}{l}\text { Demand Incidence } \\
\text { per 100000 } \\
\text { per year }\end{array}$ \\
\hline Caucasian & Male & 151 & 76 \\
& Female & 261 & 116 \\
Asian & Male & 79 & 146 \\
& Female & 84 & 159 \\
\hline
\end{tabular}

Table 2 Age specific demand incidence rates by race and sex

\begin{tabular}{|c|c|c|c|c|}
\hline \multirow{3}{*}{ Age } & \multicolumn{4}{|c|}{$\begin{array}{l}\text { Average demand incidence } \\
\text { per } 100000 \text { per year }\end{array}$} \\
\hline & \multicolumn{2}{|c|}{ Caucasian } & \multicolumn{2}{|l|}{ Asian } \\
\hline & Male & Female & Male & Female \\
\hline $16-29$ & 6 & 2 & 12 & 4 \\
\hline $30-44$ & 7 & 13 & 18 & 6 \\
\hline $45-59$ & 67 & 14 & 212 & 291 \\
\hline $60-64$ & 88 & 114 & 803 & 1098 \\
\hline $65-69$ & 252 & 243 & 746 & 1810 \\
\hline $70-74$ & 283 & 361 & 2170 & 1897 \\
\hline $75-79$ & 350 & 631 & 1963 & 1159 \\
\hline $80+$ & 333 & 524 & 3571 & 1482 \\
\hline
\end{tabular}

obtained, together with the age adjusted relative rates given in Table 3 . Averaged across all age groups the demand incidence of cataract is significantly higher in Indians than Caucasians $(\mathrm{p}<0 \cdot 0001)$. Men

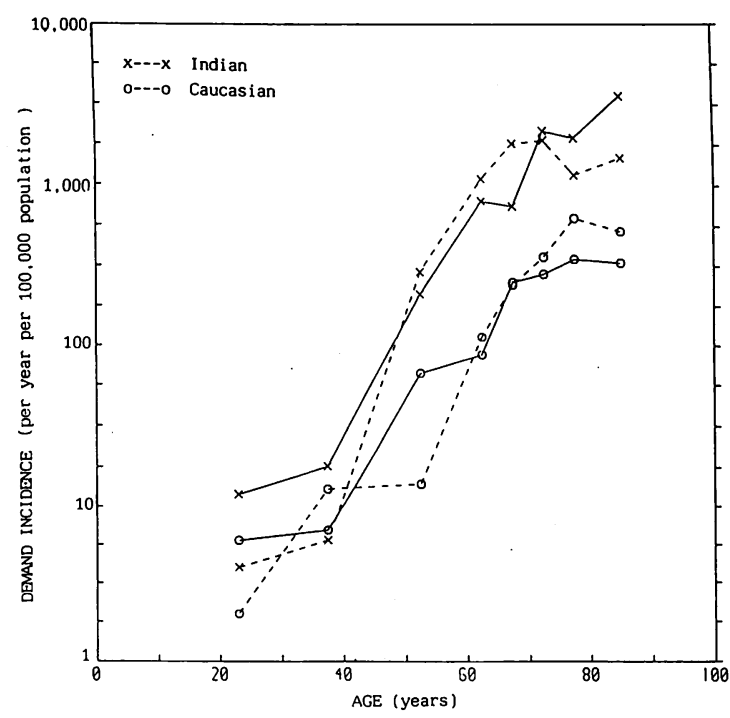

Fig. 1 The observed age specific demand incidence rates for Indians and Caucasians. Males: solid line. Females: broken line. 


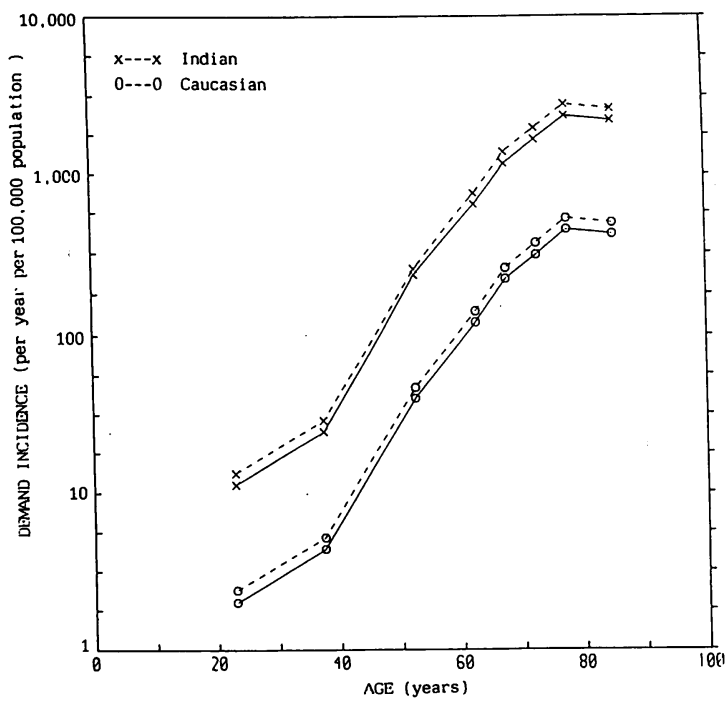

Fig. 2 The smoothed age specific demand incidence rates for Indians and Caucasians. Males: solid line. Females: broken line.

and women show the same relative rate due to race, estimated at 5.4 with a $95 \%$ confidence interval of $(4 \cdot 4,6 \cdot 5)$. The rate for women is about $20 \%$ higher in both racial groups, a difference that just reaches conventional significance levels $(p=0.05)$.

Although the relative rate averaged across all age groups is estimated as $5 \cdot 4$, there is evidence of a significant difference in the relative rate between people aged under 45 and those aged 45 and over $(p=0.004)$. For people under 45 the estimated demand incidence rate for cataract is estimated to be 1.6 times higher in Indian immigrants than in the Caucasian population. This difference is not significant. In contrast, for people aged 45 and over the relative rate is estimated as $\mathbf{5 \cdot 7}$, a highly significant difference $(p=0 \cdot 0001)$.

Fig. 3 shows the smoothed rates for those immigrants who came directly from the Indian subcontinent as compared with those who came from East Africa. The corresponding age adjusted demand incidence rates for cataract are given in Table 4 . The rates are significantly higher in those who came from India $(p=0.001)$. The relative rate is the same for

Table 3 Age adjusted relative demand incidence rates of cataract by race and sex

\begin{tabular}{lll}
\hline & Male & Female \\
\hline Caucasian & $1 \cdot 0$ & $1 \cdot 2$ \\
Asian & $5 \cdot 4$ & $6 \cdot 3$ \\
\hline
\end{tabular}

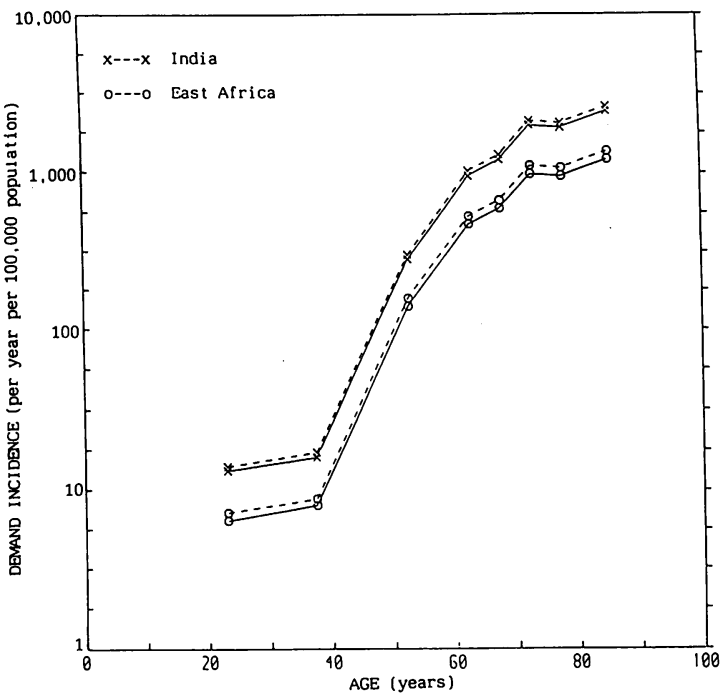

Fig. 3 The smoothed age demand incidence rates for Indian immigrants from India and from East Africa. Males: solid line. Females: broken line.

men and women and is estimated at $2 \cdot 1$ with a $95 \%$ confidence interval of $(1 \cdot 1,3 \cdot 9)$.

The division of the demand incidence rates by religious subgroup (Table 5 , Fig. 4) is significant ( $p<0 \cdot 0001$ ), but the difference is due to the contrast between Indians and Caucasians. The difference between Hindus and the other Indian groups is not significant $(p=0 \cdot 13)$.

\section{Discussion}

The use of existing sources of data is a common method of epidemiological investigation and an important stage in the planning of more rigorous surveys. However, such studies are often subject to

Table 4 Age adjusted relative demand incidence rates of cataract for Asians by region of birth and sex

\begin{tabular}{lll}
\hline & Male & Female \\
\hline East Africa & $1 \cdot 0$ & $1 \cdot 1$ \\
India & $2 \cdot 1$ & $2 \cdot 2$ \\
\hline
\end{tabular}

Table 5 Age adjusted relative rates of cataract by racial subgroup and sex

\begin{tabular}{|c|c|c|}
\hline & Male & Female \\
\hline Caucasian & $1 \cdot 0$ & $1 \cdot 2$ \\
\hline Asian: Hindu & $5 \cdot 6$ & 6.9 \\
\hline Sikh or Moslem & $4 \cdot 8$ & $4 \cdot 6$ \\
\hline
\end{tabular}




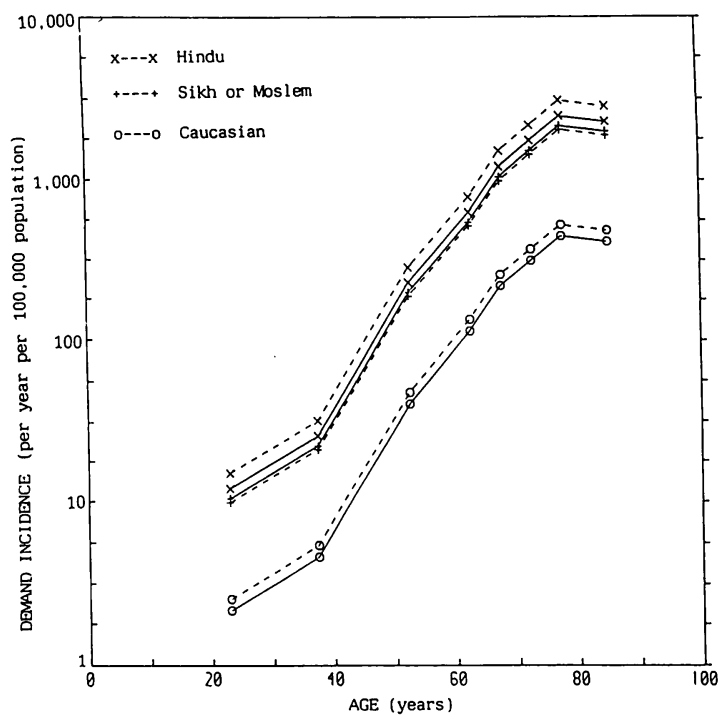

Fig. 4 The smoothed age specific demand incidence rates for Caucasians, Hindus, and Sikhs and Moslems combined. Males: solid line. Females: broken line.

bias, and in this particular study it was necessary to consider whether the outpatient clinics saw all potential cataracts, whether the diagnoses are reliable, and whether the population figures are accurate.

In order to ensure as complete a coverage as possible the target population used for the study was defined as adults resident within the city boundaries. Treatment of Leicester residents by other centres is unlikely to be a problem, but a number of people do opt for private treatment and would then not be seen at the outpatient clinics. A survey in the neighbouring city of Coventry worked with an estimated rate of $5 \%$ private treatment. ${ }^{24}$ Such a rate, even if disproportionately divided between the Indian and white communities, would be insufficient to explain the differences found in this study.

The outpatient clinics were run by a number of different ophthalmologists over the two and a half years of the study, and there may have been differences in their diagnosis of cataract. The little research that has been conducted ${ }^{2526}$ shows a good agreement between ophthalmologists in the detection of signs of cataract, and consequently variation in diagnosis may not be a major problem.

The effect of using population estimates has been studied elsewhere. ${ }^{27}$ Provided the population estimates are not biased, their effect will be to increase the variability associated with the estimates of relative risk with only small impact on the sizes of the relative risks.

Bearing in mind the limitations of the data, we must judge the epidemiological significance of this study with care, but we believe that the data give us a true overall picture. The demand incidence found in Leicester and the variation with age are both very similar to those found in Coventry in 1972..+

The results of this study show a relative demand incidence for cataract between Asians and Caucasians that is very much in line with the relative rates observed in separate studies in India and in industrialised countries. It would appear, therefore, that the previously reported differences derived from separate studies are not due to methodological effects, differences in definition, or inequalities in the standard of health care available at the time of diagnosis.

The significantly lower relative rates in people aged under 45 years is encouraging, because it may reflect the early benefits of improved health care and better standard of living experienced by the Indian immigrants. However, the possibility that the aetiology of cataract may be different for young adults requires that the relative rates be followed up carefully over the coming decades.

The difference in rate observed between people from India and people from East Africa may be due to the nature of the immigration of the two groups. People came to Britain from India to achieve a better standard of living, whereas those from East Africa were mostly expelled for political reasons. As a consequence those from India tend to be from lower socioeconomic groups, while the East Africans are a cross-section of society. ${ }^{2 \mathrm{~T}}$ The difference in rates of cataract would be consistent with a social class gradient, perhaps indicating better diet and health care.

The difference between Hindus and other Indian religious groups is not significant $(p=0 \cdot 13)$, but this comparison lacks power and a difference cannot be discounted. As Table 6 shows, vegetarianism is much more common in Hindus, and we agree with other investigators that this is a risk factor that deserves further study. Lack of protein in the diet was identified as a risk factor for cataract in one Indian study, ${ }^{3}$ and vegetarianism in Indian immigrants to Britain has been suggested as an explanation for below average growth rates in childre ${ }^{24}$ and high rates of ischaemic heart disease. ${ }^{31}$

Table 6 The percentage of Leicester residents in each racial group who do not eat meat

\begin{tabular}{llr}
\multicolumn{2}{c}{ Caucasian } & $1 \%$ \\
Asian: & Hindu & $34 \%$ \\
& Sikh & $9 \%$ \\
& Moslem & $9 \%$
\end{tabular}


Although they could not be allowed for in this analysis, there is good evidence to suggest that diabetes, cardiovascular disease, and high blood pressure are all general risk factors for cataract. . $^{-79} \mathrm{lt}$ A number of studies have noted the increased prevalence of diabetes in Indians, ${ }^{31-33}$ and it is likely that this is a factor contributing towards the increased rate of cataract.

The results of this study highlight the impact of immigration on the workload of the ophthalmic services in Leicester. They also indicate a number of risk factors that are worthy of further study. These factors are being investigated in a community survey of eye disease in Leicester.

This work was in part funded by the Anne Allerton fund. I should like to thank the referees for their helpful comments.

\section{Referencés}

1 Kornweig AL, Feldstein M, Schneider J. The eye in old age IV: Ocular survey of over 1000 aged persons with special reference to normal and disturbed visual function. Am J Ophthalmol 1957 . 44: 29-37.

2 Dhir SP, Gupta SB. Agarwal LP. Eye disease in rural India. Orient Arch Ophthalmol 1969; 7: 85-92.

3 Chatterjee A, Milton RC. Thyle S. Prevalence and aetiology of cataract in Punjab. Br J Ophthalmol 1982; 66: 35-42.

4 Raizada IN, Mathur A, Narang SK. A study of prevalence and risk factors of senile cataract in rural areas of Western UP. Indian J Ophthalmol 1984; 32: 339-42.

5 Kahn HA, Leibowitz HM, Ganley JP, et al. The Framingham eye study I: Outline and major prevalence findings. Am J Epidemiol 1977; 106: 117-32.

6 Kahn HA, Leibowitz HM, Ganley JP, et al. The Framingham eye study II: Association of ophthalmic pathology with single variables previously measured in the Framingham heart survey. Am J Epidemiol 1977: 106: 133-41.

7 Hiller R, Sperduto R, Ederer F. Epidemiologic associations with cataract in the 1971-72 National Health and Nutrition Examination Survey. Am J Epidemiol 1923; 118: 239-49.

8 Leske MC, Sperduto RD. The epidemiology of senile cataracts: a review. Am J Epidemiol 1983; 118: 152-65.

9 Clayton RM, Cuthbert J, Seth J, Phillips CI, Bartholomew RS Reid JM. Epidemiological and other studies in the assessment of factors contributing to caractagenesis. In: Nugent J, Whelan J, eds. Human cataract formation. Ciba Foundation Symposium 106. London: Pitman, 1984.

10 Department of Health and Social Security. Blindness and partial sight in England 1969-1976. DHSS Reports on public health and medical subjects No. 129. London: HMSO, 1978.

11 Duke-Elder S. System of ophthalmology. London: Kimpton, 1969: 11

12 Bunce G. Nutrition and cataract. Nutr Rev 1979; 37: 337-43.
13 Hiller R, Giacometti L, Yuen K. Sunlight and cataract: an epidemiological investigation. Am J Epidemiol 1977; 105: 45()-9.

14 Brilliant LB, Grasset NC. Pokhrel RP, et al. Associations between cataract prevalence, sunlight hours and altitude in the Himalayas. Am J Epidemiol 1983; 118 : 250-64.

15 Kharmar BK, Rawal UM. Sunlight - its etiological role in cataract formation. Indian J Ophthalmol 1983; 31: 842-3.

16 Ederer F, Hiller R, Taylor HR. Senile lens changes and diabetes in two population studies. Am J Ophthalmol 1981: 91: 381-95.

17 Harding J. Possible causes of the unfolding of proteins in cataract and a new hypothesis to explain the high prevalence in some countries. In: Regnault F, Hockwin O, Courtois Y, eds. Ageing of the lens. Amsterdam: North Holland Biometrical Press, 1980.

18 Chiapella AP, Rosenthal AR. One year in an eye casualty clinic. Br J Ophthalmol 1985; 69: 865-70.

19 World Health Organisation. Manual of the international statistical classification of diseases, injuries and cause of death. Geneva: WHO, 1977.

20 Working group for the Survey of Leicester. Survey of Leicester 1983: initial report of the survey. Leicester City Council and Leicestershire County Council, 1985.

21 Mantel N, Stark CR. Computation of indirect-adjusted rates in the presence of confounding. Biometrics 1968: 24: 997-10)5.

22 Breslow NE, Day NE. Indirect standardisation and multiplicative models for rates with reference to the age adjustment of cancer indicence and relative frequency data. J Chronic Dis 1975 ; 28: $289-303$

23 Baker RJ, Nelder JA. General linear interactive modelling (GLIM) release 3. 77. 2nd ed. Oxford: Numerical Algorithms Group, 1987.

24 Brennan M, Knox B. The incidence of cataract and its clinical presentation. Community Health 1975; 7: 13-20.

25 Brilliant LB, Lepowski JM, Musch DC. Reliability of ophthalmic diagnoses in an epidemiological survey. Am J Epidemiol 1983; 118: 265-79.

26 Gibson RA, Sanderson HF. Observer variation in ophthalmology. Br J Ophthalmol 1980; 64: 457-60.

27 Thompson JR. Indirect standardization when the person-years data are subject to error. Internal Report, Department of Ophthalmology. University of Leicester, 1988.

28 Marmot MG, Adelstein AM, Bulusu L. Immigrant mortality in England and Wales 1970-1978. OPCS Studies on Medical and Population Subjects 47. London: HMSO, 1984.

29 Rona RJ, Chinn S, Duggal S, Driver AP. Vegetarianism and growth in Urdu, Gujarti, and Punjabi children in Britain. $J$ Epidemiol Community Health 1987; 41: 233-6.

30 McKeigue PM, Adelstein AM, Shipley MJ, et al. Diet and risk factors for coronary heart disease in Asians in Northwest London. Lancet 1985; ii: 1086-90.

31 Samanta A, Burden AC, Jones GR, et al. Prevalence of known diabetes in Asians and Europeans. Br Med J 1985; 291: 1571-2.

32 Gupta OP, Joshi MJ, Dave SK. Prevalence of diabetes in India. In: Miller M, Bennett PH, eds. Advances in metabolic disorders. New York: Academic Press, 1978.

33 Mather HM, Keen H. The Southall diabetes survey: prevalence of known diabetes in Asians and Europeans. Br Med J 1985; 291: $1081-4$.

Accepted for publication 2 June 1989. 